\title{
Analysis of the effect of polarization traps and shallow impurities on the interlevel light absorption of quantum dots
}

\author{
V.I. Boichuk, R.Ya. Leshko, D.S. Karpyn \\ Department of Theoretical and Applied Physics, and Computer Simulation, Ivan Franko Drohobych State \\ Pedagogical University, 3 Stryiska St., 82100 Drohobych, Ukraine
}

Received March 20, 2017, in final form May 27, 2017

\begin{abstract}
A spherical quantum dot (QD) heterosystem $\mathrm{CdS} / \mathrm{SiO}_{2}$ has been studied. Each QD has a hydrogen-like impurity in its center. Besides that, it has been accounted that a polarization trap for electron exists at the interfaces due to the difference between the QD and matrix dielectric permittivity. It has been defined that for small QD radii there are surface electron states. For different radii, partial contributions of the surface states into the electron energy caused by the electron-ion and electron-polarization charges interaction have been defined. The linear light absorption coefficient of noninteracting QDs has been calculated taking into account the QD dispersion by the size. It is shown that the surface states can be observed into different ranges of an electromagnetic spectrum.
\end{abstract}

Key words: absorption coefficient, donor impurity, polarization trap

PACS: 73.21.La, 78.20.Ci

\section{Introduction}

It is a long period of time that the physics of nanosystems is considered to be a priority direction in the modern development of the materials science and nanoelectronics. Its success is due to the use of nanoobjects such as quantum films, quantum wires, quantum rings and especially quantum dots (QDs). Due to their unique properties, QDs are widely used in optoelectronics. The narrow spectrum of radiation of monodisperse QDs makes it possible to use QDs in light-emitting diodes (LEDs). They have better spectral characteristics and a higher coefficient of efficiency than LEDs on the basis of the liquid crystals and organics materials [1].

In experimental works it was defined [1, 2] that the use of the nanocrystals of CdS, CdTe, CdSe makes it possible to get an emission band in a visible spectrum. Those emission peaks are connected with exciton luminescence. Moreover, the range of size of QDs in that work was 2-8 nm. In that and other works [3-6], authors assure that except excitonic peaks there is a wide luminescence band which is caused by the impurity and surface states.

There are many theoretical works which are devoted to the study of shallow donor and acceptor impurity states, in nanosystems of different shapes [7- [15]. It was proved that by decreasing the QD radius to the value less than the corresponding effective Bohr radius, the probability of electron residence outside QD is larger than in the QD. In this case, there are bound states outside the QD.

An increasing ratio of the number of atoms on the surface to the number of atoms in the nanocrystal volume (QD size becomes small) increases the role of the surface states in the formation of absorption and luminescence bands. It relates to the heterosystem with CdS QDs. Notwithstanding that in CdS QD it is often hard to determine the nature of the surface states, in most cases the red radiation spectrum is caused by electron transition with concern to the surface traps [16]. One of the reasons for the existence of a surface trap is the polarization charges on the interfaces. The value of polarization charges and 
the potential energy of the electron interaction with polarization charges are defined by the difference of the dielectric permittivity of a heterosystem. A larger difference of the dielectric permittivity of a heterosystem and smaller sizes of QDs increase the role of the polarization trap.

Thus, the aim of this work is to determine the following:

- the interface states of the QD with hydrogen-like impurity in the center of the QD;

- the effect of the surface states of the QD on the interlevel light absorption which is caused by the transitions between the inner and the outer (interface) states.

\section{The energy spectrum of the electron in a small QD with impurity}

Let us consider the $\mathrm{CdS} / \mathrm{SiO}_{2}$ heterosystem (table 1 in the appendix) consisting of a dielectric or semiconductor matrix that contains spherical QDs with a hydrogen-like impurity in the QD center. The charged particle is characterized by its own effective mass in each medium $\left(m_{1}^{*}, m_{2}^{*}\right)$. The media are described by their own dielectric permittivity $\left(\varepsilon_{1}, \varepsilon_{2}\right)$.

Modern technology is capable of obtaining a sufficient quality of semiconductor and dielectric nanoheterostructures. In reality, it is difficult to create a heterogeneous system with a sharp change of all physical parameters at the interface. There is always an intermediate layer in which a particular physical parameter (particle's effective mass, dielectric constant) varies from its value in some crystal to the corresponding value in the other crystal.

Let us assume that at the interface there exists a transitional layer where dielectric permittivity changes from its value in the QD to the corresponding matrix value. In this case, one may obtain the potential energy of the charge particle interaction with polarization charges as follows [17]:

$$
\begin{aligned}
V_{\mathrm{p}}(r)= & \frac{\gamma}{4 \varepsilon(r)} \int_{0}^{\infty} \mathrm{d} r_{0} \frac{\tanh \left(\frac{r_{0}-a}{L}\right)+\frac{r_{0}}{L} \operatorname{sech}^{2}\left(\frac{r_{0}-a}{L}\right)}{r_{0}^{2}-r} \\
& +\frac{\gamma^{2}}{8 \pi \varepsilon(r)} \int_{0}^{\infty} \mathrm{d} r_{0} \frac{\frac{2 r_{0}}{L} \operatorname{sech}^{2}\left(\frac{r_{0}-a}{L}\right) \tanh \left(\frac{r_{0}-a}{L}\right)+\tanh ^{2}\left(\frac{r_{0}-a}{L}\right)}{r_{0}^{2}-r^{2}} \\
& +\frac{\gamma^{2}}{16 \pi \varepsilon(r) r} \int_{0}^{\infty} \mathrm{d} r_{0} \ln \left|\frac{r_{0}+r}{r_{0}-r}\right| \frac{1}{r_{0}}\left[\frac{2 r_{0}}{L} \operatorname{sech}^{2}\left(\frac{r_{0}-a}{L}\right) \tanh \left(\frac{r_{0}-a}{L}\right)+\tanh ^{2}\left(\frac{r_{0}-a}{L}\right)\right] \\
& +\frac{\gamma^{2}}{4 \pi \varepsilon(r) r} \int_{0}^{r} \mathrm{~d} r_{0} \tanh \left(\frac{r_{0}-a}{L}\right)+\frac{r_{0}}{L} \operatorname{sech}^{2}\left(\frac{r_{0}-a}{L}\right) \\
& \times \int_{r}^{\infty} \mathrm{d} r_{1} \frac{1}{r_{0}^{2}+r_{1}^{2}}\left[\frac{r_{1}}{L} \operatorname{sech}^{2}\left(\frac{r_{1}-a}{L}\right)+\tanh \left(\frac{r_{1}-a}{L}\right)\right], \\
\gamma & \varepsilon(r)=\frac{\varepsilon_{1}+\varepsilon_{2}}{2}\left[1-\gamma \tanh \left(\frac{r-a}{L}\right)\right],
\end{aligned}
$$

We used Hartree units $\left(m_{0}=1, \hbar=1, e=1\right)$. Based on the formula 2.1$)$, the analysis shows that the transitional layer width is approximately equal to the crystal constant $a_{0}$, if $L \leqslant 1 / 4 \cdot a_{0}$. $L$ is the theory parameter which determines the transition layer width. In the case of the matrix near the QD surface, there is a potential well which is called a polarization trap.

We consider the electron of spherical QD CdS in the matrix $\mathrm{SiO}_{2}$. The Hamiltonian of the heterosystem has the form:

$$
\hat{\mathbf{H}}=-\frac{1}{2} \boldsymbol{\nabla} \frac{1}{m(r)} \boldsymbol{\nabla}+U(r)+V(r)+V_{\mathrm{p}}(r)=\hat{\mathbf{H}}^{0}+V_{\mathrm{p}}(r),
$$


where the confinement potential is

$$
U(r)=\left\{\begin{array}{ll}
0, & r \leqslant a, \\
U_{0}, & r>a,
\end{array} \quad U_{0}>0,\right.
$$

where $a$ is QD radius, and the potential energy $V_{\mathrm{p}}(r)$ is expressed by 2.1 . Also, the impurity ion interacts with the electron. The potential energy of this interaction was derived from the Poisson equation and has the form

$$
V(r)= \begin{cases}-\frac{1}{\varepsilon_{1} r}-\frac{\varepsilon_{1}-\varepsilon_{2}}{\varepsilon_{1} \varepsilon_{2} a}, & r \leqslant a, \\ -\frac{1}{\varepsilon_{2} r}, & r>a .\end{cases}
$$

The total electron potential energy is plotted in figure 1

The Schrödinger equation with Hamiltonian $\hat{\mathbf{H}}^{0}$ can be solved exactly [13]. Solutions can be expressed in two different regions of $r$ :

$$
\psi^{(0)}(r, \Omega)= \begin{cases}\psi_{1}(r, \Omega), & r \leqslant a, \\ \psi_{2}(r, \Omega), & r>a,\end{cases}
$$

where $\Omega$ is a solid angle.

Let $r \leqslant a$. Then,

$$
\psi_{1}\left(\xi_{1}, \Omega\right)=A_{1} M_{\lambda_{1}, l+1 / 2}\left(\xi_{1}\right) / \xi_{1} \cdot Y_{l}^{m}(\Omega)
$$

if

$$
\tilde{E}_{1}=E+\frac{\left(\varepsilon_{1}-\varepsilon_{2}\right)}{\varepsilon_{1} \varepsilon_{2} a}<0
$$

where $\xi_{1}=\alpha_{1} r,\left(\alpha_{1}\right)^{2}=-8 m_{1}^{*} \tilde{E}_{1}, \lambda_{1}=2 m_{1}^{*} /\left(\varepsilon_{1} \alpha_{1}\right), M$ is Whittaker function, or

$$
\psi_{1}\left(\xi_{1}, \Omega\right)=A_{1} F_{l}\left(\delta_{1}, \xi_{1}\right) / \xi_{1} \cdot Y_{l}^{m}(\Omega),
$$

if

$$
\tilde{E}_{1}=E+\frac{\left(\varepsilon_{1}-\varepsilon_{2}\right)}{\varepsilon_{1} \varepsilon_{2} a}>0
$$

where $\xi_{1}=\beta_{1} r, \beta_{1}^{2}=2 m_{1}^{*} \tilde{E}_{1}, \delta_{1}=-m_{1}^{*} /\left(\varepsilon_{1} \beta_{1}\right), F$ is a regular Coulomb function. On condition that $r>a$

$$
\psi_{2}\left(\xi_{2}, \Omega\right)=D_{2} W_{\lambda_{2}, l+1 / 2}\left(\xi_{2}\right) / \xi_{2} \cdot Y_{l}^{m}(\Omega)
$$

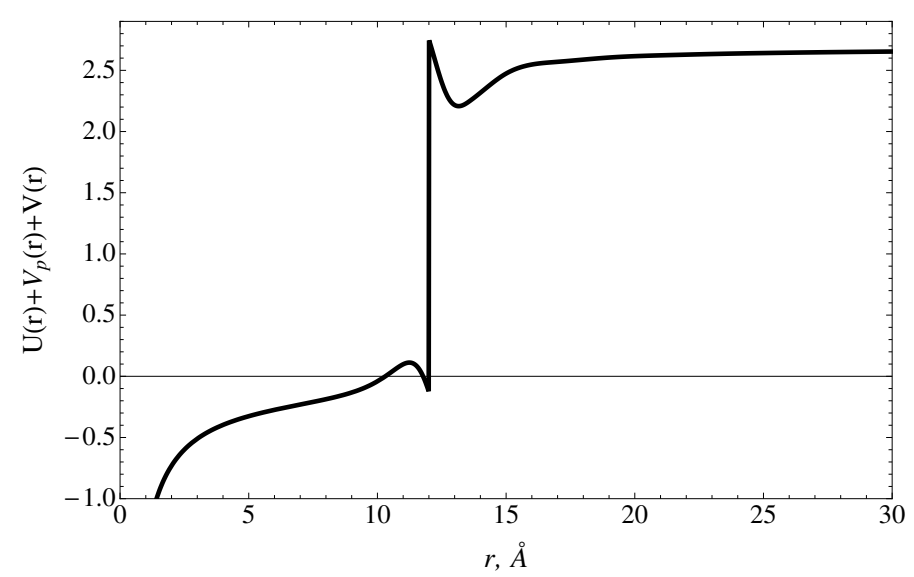

Figure 1. The electron potential energy as a function of $r$ in the QD heterosystem $\mathrm{CdS} / \mathrm{SiO}_{2}$. QD radius $a=12 \AA, L=a_{0} / 4$. 

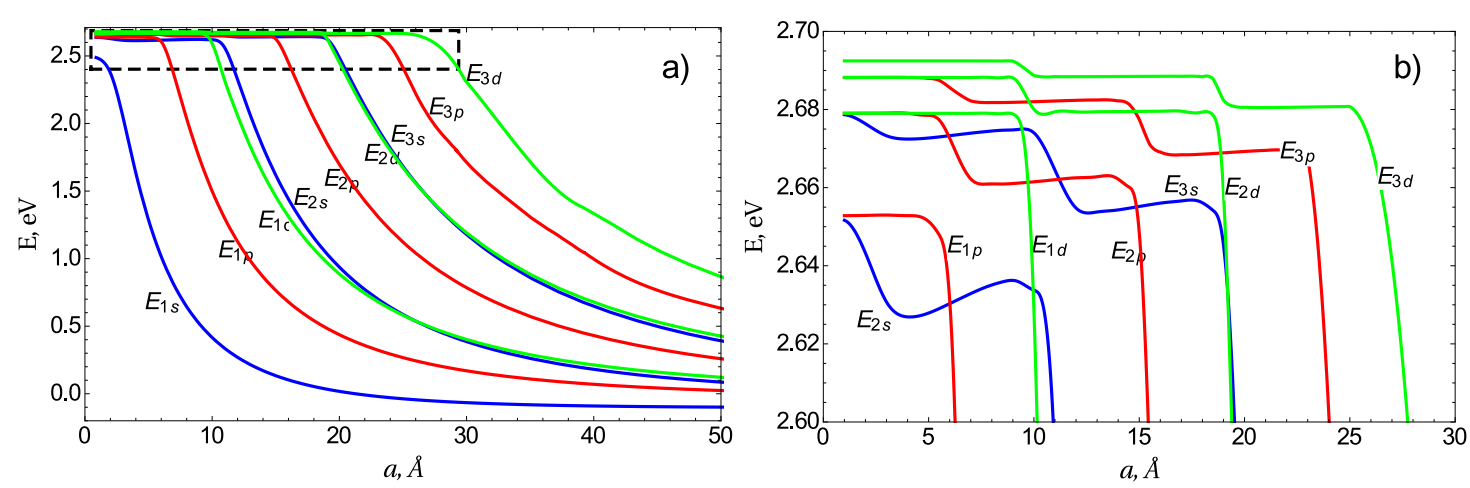

Figure 2. (Color online) The electron energy in the QD. Figure (b) shows the box from figure (a).

where $\xi_{2}=\alpha_{2} r,\left(\alpha_{2}\right)^{2}=-8 m_{2}^{*} \tilde{E}_{2}, \lambda_{2}=2 m_{2}^{*} /\left(\varepsilon_{2} \alpha_{2}\right), \tilde{E}_{2}=E-U_{0}<0, W$ is the other Whittaker function, which tends to zero, if $r \rightarrow \infty$.

Using the boundary conditions and a normalizing condition

$$
\begin{gathered}
\left.R_{1}(r)\right|_{r=a}-\left.R_{2}(r)\right|_{r=a}=0, \\
\left.\frac{1}{m_{1}^{*}} \frac{\partial}{\partial r} R_{1}(r)\right|_{r=a}-\left.\frac{1}{m_{2}^{*}} \frac{\partial}{\partial r} R_{2}(r)\right|_{r=a}=0, \\
\int \mathrm{d} \vec{r}|\psi(r, \theta, \varphi)|^{2}=1,
\end{gathered}
$$

the energy spectrum of the electron is calculated and all the constants are found.

The calculation results of the electron for $s-, p-, d$-states were presented in figure 2 . From the graphs it is seen that for each state there is a range where a decrease of the QD radius leads to a particle energy increase due to a space confinement.

A decrease of the QD radius shows that for some range of the radii of QD, the energy of each state reaches some values, where it does not depend on $a$. According to the number of energy levels there are several regions of radii. These energy dependences on the QD radius can be explained by the fact that for a specific state, the QD radius decrease is accompanied by a push of the energy level from the quantum well. In this case, the electron energy monotonously increases. When the probability density of the particle has its maximum in the matrix near the interface (in the surface state) its energy does not depend on the QD radius. From figure 2 (b) it is seen that each lower surface level "pushes" the upper level of that type. And we have got sets of levels that correspond to hydrogen-like energy levels.

The above described results were obtained from the exact solution of the Schrödinger equation with $\hat{\mathbf{H}}^{0}$. The surface states were caused only by the ion of impurity which keeps an electron in the matrix near the interface. In a real heterosystem, there are polarization charges that influence the surface states. The Schrödinger equation with Hamiltonian (2.4) can be solved taking polarization charges into consideration. The wave function which is a solution to the Schrödinger equation with Hamiltonian (2.4) is expressed by the expansion over the function $(2.77$ :

$$
\Psi=\sum_{i} C_{i} \psi_{i}^{(0)},
$$

$i$ is the quantum number set $n, l, m$. Our task reduces to the linear system of equations

$$
\sum_{i} C_{i}\left\{\left[E_{i}^{(0)}-E\right] \delta_{j i}+\left\langle\psi_{j}^{(0)}\left|V_{\mathrm{p}}\right| \psi_{i}^{(0)}\right\rangle\right\}=0
$$

From (2.13) and from the normalizing condition, all $C_{i}$ and the energy of the system have been found. The calculation results are presented in figure 3 . 


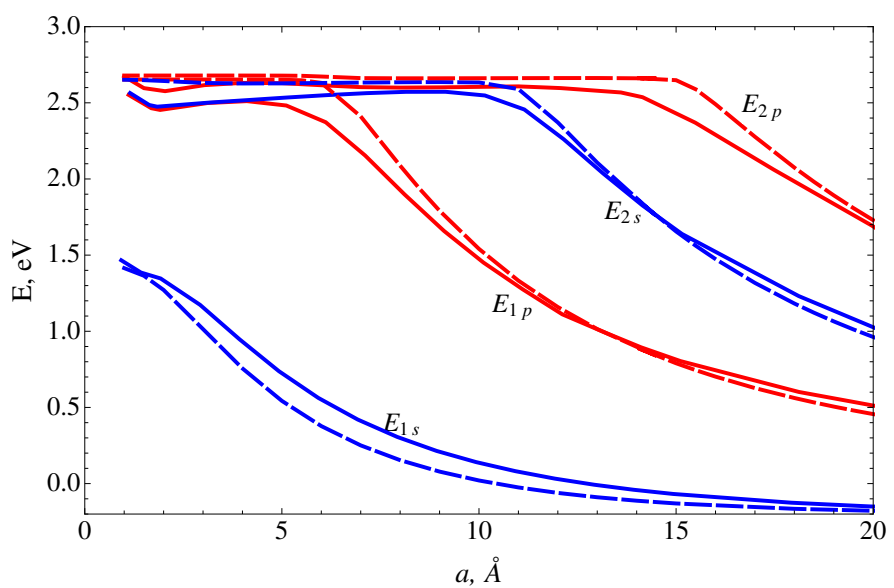

Figure 3. (Color online) Impurity electron energy with regard to the polarization charges (solid curves) and with a neglect of the polarization charges (dashed curves).

Figure 3 shows that the polarization charges being taken into consideration increase the electron energy for the inner-dot states. In this case, we receive the known result [13, 17]: if the QD dielectric permittivity is larger than the matrix one, the QD energy increases. However, for small QD radii, taking the polarization charges into consideration decreases the electron energy. This result can be understood when one sees the potential $\sqrt{2.1}$ plotted in figure 1 for QD radius $12 \AA$. Figure 1 shows that outside the QD, there is a potential well (polarization trap). Obviously, at the small QD sizes, the electron gets into the polarization trap due to the confinement. Hence, taking the polarization charges into account for small QD radii decreases the electron energy. Therefore, the polarization charges and the ion of impurity are two independent reasons for the existence of surface states. As one can see from figure 3 , for very small QD radii (less than $10 \AA$ ), the results are only of theoretical interest, but they do not contradict to the resolution made above. The crystals exist where the above mentioned effects are observed for larger QD radii. This depends on the effective Bohr radius $\left(a_{b}^{*}\right)$. For CdS $a_{b}^{*}=14.5 \AA$.

Let us calculate the absorption of electromagnetic waves caused by the electron interlevel transition from some $|i\rangle$ state into $|f\rangle$ state. Let the heterosystem be irradiated by a linear polarized light. Then, in the dipole approximation, the selection rules are $\Delta l= \pm 1$ and $\Delta m=0$. By the use of formulae from [9], we write the light absorption coefficient for the heterosystem:

$$
\alpha_{i, f}(\omega)=\omega \sqrt{\frac{\mu_{0}}{\varepsilon_{0} \varepsilon}} \frac{N\left|d_{i f}\right|^{2} \hbar \Gamma}{\left(E_{f}-E_{i}-\hbar \omega\right)^{2}+(\hbar \Gamma)^{2}},
$$

where $\varepsilon_{0}$ is electric constant, $\mu_{0}$ is magnetic constant, $d_{i f}$ is matrix element of dipole moment, $N$ is carrier concentration. The concentration of the QDs in the matrix was chosen according to the value that provides the case when the interaction between QDs can be neglected. $\hbar \Gamma$ is relaxation rate. If $T \approx 4 \mathrm{~K}$, then $\hbar \Gamma \rightarrow 0$ :

$$
\alpha_{i, f}(\omega)=\lim _{\hbar \Gamma \rightarrow 0}\left[\omega \sqrt{\frac{\mu_{0}}{\varepsilon_{0} \varepsilon}} \frac{N\left|d_{i f}\right|^{2} \hbar \Gamma}{\left(E_{f}-E_{i}-\hbar \omega\right)^{2}+(\hbar \Gamma)^{2}}\right]=\omega \pi \sqrt{\frac{\mu_{0}}{\varepsilon_{0} \varepsilon}} N\left|d_{i f}\right|^{2} \delta\left(E_{f}-E_{i}-\hbar \omega\right),
$$

2.15) is valid only for a system of QDs which has an identical size. However, in practice, the sets of QDs have a dispersion by size. The QD size distribution can be approximated by the Lifshits-Slezov or Gauss function. We use Gauss function:

$$
g(s, \bar{a}, a)=\frac{1}{s \sqrt{2 \pi}} \exp \left[-\frac{(a-\bar{a})^{2}}{2 s^{2}}\right],
$$

where $a$ is the QD radius (variable), $s$ is half-width of the distribution 2.16, which is expressed by the average radius $\bar{a}$ and the value $\sigma$ which is considered as the variance in the QD sizes expressed in 


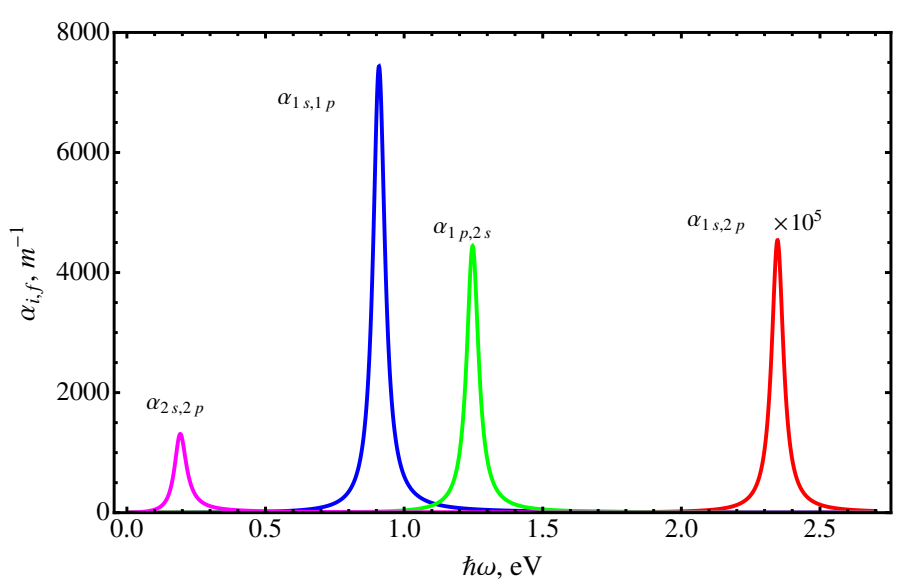

Figure 4. (Color online) Light absorption coefficient caused by the electron interlevel transition.

percentage: $s=\bar{a} \sigma / 100$. By taking the QD dispersion into account 2.16, the absorption coefficient is obtained as follows:

$$
\alpha_{i, f}(\omega)=\omega \pi \sqrt{\frac{\mu_{0}}{\varepsilon_{0} \varepsilon}} N \sum_{j} \frac{g\left(s, \bar{a}, a_{0 j}\right)\left|d_{i f}\left(a_{0 j}\right)\right|^{2}}{\left|\frac{\mathrm{d}}{\mathrm{d} a}\left[E_{f}(a)-E_{i}(a)-\hbar \omega\right]\right|_{a=a_{0 j}}},
$$

where $a_{0 j}$ are simple zeros of the function $Q(a)=E_{f}(a)-E_{i}(a)-\hbar \omega$.

The dependence of the absorption coefficient on the quant energy of light for an average radius $11.64 \AA$ (two crystals parameters $a_{0}, N \approx 3 \cdot 10^{16} \mathrm{~cm}^{-3}$ ) and dispersion $\sigma=5 \%$ is shown in figure 4 . Figure 4 shows that the light absorption coefficient is caused by the transition from the ground state into the surface state $(1 s-2 p)$ and is 5-6 orders less than the transition from the other inner-dot states into exited states. The reason for this is the distance between the energy levels, which is larger than in the case of transition $(1 s-1 p)$ while the dipole momentum of interlevel transition is smaller.

Furthermore, the transition from the ground state into the first exited state $(1 s-1 p)$ for this value is larger and is located by the energy scale far from the next possible transition from the ground state to the exited $2 p$-state $(1 s-2 p)$.

\section{Conclusion}

The calculation of the electron energy in the QD heterosystem with an impurity shows that the reduction of the QD size causes a transformation of the lowest exited states from the inner-dot into the outer-dot states. The outer-dot states are characterised by a weak energy dependence on the QD radius. The probability density of the electron in the space for those states has a maximum value near the QD surface in the matrix. Those states are called "surface electron states".

Taking into account the polarization charges and the intermediate layer with $\varepsilon=\varepsilon(r)$ on the surface, causes the existence of the electron polarization trap in the matrix near the QD surface. It has been defined that the electron interaction with polarization charges increases the binding energy of the surface states (decreases the electron energy). For example, for $a=15 \AA$, the electron binding energy for the surface $2 p$-state equals $94 \mathrm{meV}$ if the potential (2.1) is neglected, and $267 \mathrm{meV}$ if the potential (2.1) is taken into account.

Based on the found wave functions of the inner-dot and outer-dot states, we calculate the light absorption coefficient for QD heterosystem $\mathrm{CdS} / \mathrm{SiO}_{2}$. With an average QD radius $\bar{a}=2 a_{0}\left(a_{0}\right.$ is the crystal parameter) there are absorption bands which have different energies $\left(E_{2 s-2 p} \approx 0.29 \mathrm{eV}\right.$, $\left.E_{1 s-1 p} \approx 0.92 \mathrm{eV}, E_{1 p-2 s} \approx 1.28 \mathrm{eV}, E_{1 s-2 p} \approx 1.37 \mathrm{eV}\right)$ and heights. 
The obtained results should be taken into consideration while analysing the experimental absorption and luminescence bands for a heterosystem with CdS QD.

\section{Appendix}

Table 1. Parameters of the heterosystem [18].

\begin{tabular}{|c|c|c|c|c|}
\hline \hline crystal & $m\left(m_{e}\right)$ & $\varepsilon$ & $a_{0}, \AA$ & $U_{0}, \mathrm{eV}$ \\
\hline \hline $\mathrm{CdS}$ & 0.2 & 5.5 & 5.818 & 0 \\
\hline $\mathrm{SiO}_{2}$ & 0.42 & 3.9 & - & 2.7 \\
\hline \hline
\end{tabular}

\section{References}

1. Korbutyak D.V., Kovalenko O.V., Budzulyak S.I., Kalytchuk S.M., Kupchak I.M., Ukr. J. Phys. Reviews, 2012, 7, No. 1, 48-95 (in Ukrainian).

2. Michalet X., Pinaud F.F., Bentolila L.A., Tsay J.M., Doose S., Li J.J., Sundaresan G., Wu A.M., Gambhir S.S., Weiss S., Science, 2005, 307, 538, doi:10.1126/science.1104274

3. Kapitonov A.M., Stupak A.P., Gaponenko S.V., Petrov E.P., Rogach A.L., Eychmüller A., J. Phys. Chem. B, 1999, 103, 10109, doi $10.1021 /$ jp9921809

4. Hoheisel W., Colvin V.L., Johnson C.S., Alivisatos A.P., J. Chem. Phys., 1994, 101, 8455, doi 10.1063/1.468107

5. Xi L., Lek J.Y., Liang Y.N., Boothroyd C., Zhou W., Yan Q., Hu X., Chiang F.B.Y., Lam Y.M., Nanotechnology, 2011, 22, 275706, doi:10.1088/0957-4484/22/27/275706.

6. Hässelbarth A., Eychmüller A., Well H., Chem. Phys. Lett., 1993, 203, 271, doi 10.1016/0009-2614(93)85400-I

7. Zhu J.-L., Chen X., Phys. Rev. B, 1994, 50, 4497, doi 10.1103/PhysRevB.50.4497

8. Polupanov A.F., Galiev V.I., Novak M.G., Fiz. Tekh. Poluprovodn., 1997, 31, 1375 (in Russian).

9. Vahdani M.R.K., Rezaei G., Phys. Lett. A, 2009, 373, No. 34, 3079, doi $10.1016 /$ j.physleta.2009.06.042

10. Boichuk V.I., Bilynskyi I.V., Leshko R.Ya., Condens. Matter Phys., 2010, 13, 13702, doi:10.5488/CMP.13.13702

11. Nasri D., Sekkal N., Physica E, 2010, 42, 2257, doi 10.1016/j.physe.2010.04.028

12. Xie W., Superlattices Microstruct., 2010, 48, 239, doi 10.1016/j.spmi.2010.04.015

13. Boichuk V.I., Bilynskyi I.V., Leshko R.Ya., Turyanska L.M., Physica E, 2011, 44, 476, doi $10.1016 /$ j.physe.2011.09.025

14. Holovatsky V.A., Frankiv I.B., J. Phys. Stud., 2012, 16, 1706 (in Ukrainian).

15. Boichuk V.I., Bilynskyi I.V., Leshko R.Ya., Turyanska L.M., Physica E, 2013, 54, 281, doi $10.1016 /$ j.physe.2013.07.003

16. Romcevic M., Romcevic N., Kostic R., Klopotowski L., Dobrowolski W.D., Kossut J., Čomor M.I., J. Alloys Compd., 2010, 497, 46, doi 10.1016/j.jallcom.2010.03.072.

17. Boichuk V.I., Kubai R.Yu., Fiz. Tverd. Tela, 2001, 43, 226 (in Russian).

18. Holovatsky V.A., Makhanets O.M., Voitsekhivska O.M., Physica E, 2009, 41, 1522, doi $10.1016 /$ j.physe.2009.04.027 


\section{Аналіз впливу поляризаційних пасток і мілких домішок на міжрівневе поглинання світла квантовими точками}

\section{В.I. Бойчук, Р.Я. Лешко, Д.С. Карпин}

Кафедра теоретичної і прикладної фізики та комп'ютерного моделювання, Дрогобицький державний педагогічний університет імені Івана Франка, вул. Стрийська, 3, 82100 Дрогобич, Україна

У роботі досліджується наногетеросистема сферичних квантових точок (KT) CdS у матриці $\mathrm{SiO}_{2}$. Кожна КТ у центрі містить водневоподібну домішку. Крім того, враховано, що біля меж поділу через різницю діелектричних проникностей виникає поляризаційна пастка для електрона. Встановлено, що для малих радіусів КТ існують поверхневі електронні стани. Для різних радіусів КТ обчислено парціальні внески в енергію зв'язку поверхневих станів від взаємодії електрона з іоном домішки та поляризаційними зарядами. Проведено обчислення коефіцієнта міжрівневого поглинання гетеросистеми з невзаємодіючими КТ, враховуючи їх дисперсію за розмірами. Показано, що поверхневі стани проявляються в різних областях спектру.

Ключові слова: донорна домішка, коефіцієнт поглинання, поляризаційна пастка 